\title{
Liken simpleks kronikusta hastalık bilgisi ve davranış geliştirmenin tedaviye etkisi
}

\section{The impact of disease information and behaviour development on the treatment of lichen simplex chronicus}

\author{
Rukiye Yasak*, Sibel Berksoy Hayta, Selma Uçar \\ Dermatoloji Kliniği (Dr. R. Yasak), Nazilli Devlet Hastanesi, Aydın, Dermatoloji Anabilim Dalı \\ (Yrd. Doç. Dr. S. Berksoy Hayta), Cumhuriyet Üniversitesi Tıp Fakültesi, TR-58140 Sivas, \\ Dermatoloji Kliniği (Uzm. Dr. S. Uçar) Anadolu Hastanesi, Sivas
}

\begin{abstract}
Özet
Amaç. Liken simpleks kronikus günlük dermatoloji pratiğinde genellikle kronik ekzema gibi değerlendirilerek tedavi edilmektedir. Bununla birlikte etyolojide temelde psikolojik faktörler yer alır. Bu çalışmamızda yaşam boyu doyum, süreklilik kaygı ve kısa dönem ankisiyetenin rolü araştırılarak hastalıkla ilgili bir davranışsal eğitimle semptomların kontrol altına alınıp alınamayacağı araştıııldı. Yöntem. Çalışmaya Dermatoloji Polikliniği'ne başvuran 21 liken simpleks kronikuslu olgu alındı. Hastalara Yaşam Doyumu Ölçeği, Beck Anksiyete Ölçeği, Sürekli Kaygı Ölçeği ve Görsel Analog Skala uygulandı. Hastalara hastalıkla ilgili bir bilgi broşürü ve topikal emolyent önerilerek iki hafta sonra kontrole çağırıldı. Kontrolde görsel analog skala ve Beck ankisiyete ölçeği tekrar uygulandı. Bulgular. Yaşam Doyumu Ölçeği, Süreklilik Kaygı Ölçeği, Beck Ankisiyete Ölçeği ve görsel analog skala değerleri arasında ilk muayenede istatistiksel olarak anlamlı bir korelasyon saptanamadı ( $>0.05)$. İlk muayene ve kontrol muayenesinde Beck Ankisiyete Ölçeği değerleri arasında istatistiksel olarak anlamlı bir fark tespit edildi. Kontrolde elde edilen Beck ankisiyete değerleri daha düşük bulundu (Z: -3,204, p<0,05). İlk muayenede ve kontrol muayenesinde elde edilen görsel analog skala değerleri karşılaştırıldığında aralarındaki fark istatistiksel olarak anlamlı bulundu $(Z=-3,683 ; p<0,05)$. Tedavi sonrası Beck ankisiyete puanları ve görsel analog skala puanları arasında istatistiksel olarak anlamlı bir korelasyon saptandı $(r=0,446 ; \mathrm{p}<0,05)$. Sonuç. Liken simpleks kronikus olgularında kısa dönemde ortaya çıkmış olan kaygı ve buna bağlı gelişen kaşıntı hissi, hastalıkla ilgili doğru ve yeterli bilgilendirmeyle azaltılabilir ve hastalığın klinik kontrolü sağlanabilir.
\end{abstract}

Anahtar sözcükler: Liken simpleks kronikus, yaşam doyumu ölçeği, süreklilik kaygı ölçeği, Beck ankisiyete ölçeği, pruritus, hasta eğitimi

\begin{abstract}
Aim. Lichen simplex chronicus in dermatology practice is often chronic and treated as chronic dermatitis. However, its etiology include psychologic factors. In this study, we investigated the role of satisfaction with life, trait anxiety and short term anxiety, and whether the impact of adequate information about the disease can control symptoms. Method. 21 patients with lichen simplex chronicus were included the study. Satisfaction with life scale, STAI-TX2, Beck anxiety inventory and visual analog scale were applied to the patients. Patients were given an information brochure about their disease and recommended an emollient. Patients were invited for control examination after two weeks. Results. There were no statistically significant correlation between satisfaction with life, STAI-TX2, Beck anxiety inventory and visual analog scale ( $>>0.05)$. There was a statistically significant different between levels of Beck anxiety in the first and control examinations (Z: $-3.204, \mathrm{p}<0.05)$. There was a statistically significant different between levels of visual analog scale in the first and control examination $(Z=-3.683, p<0.05)$. There were significant correlations between beck anxiety scores and visual analog scale scores in the first and control examinations $(r=0.446, \mathrm{p}<0.05)$. Conclusion. In cases of lichen simplex chronicus, emerging immediately itching sensation resulted from anxiety may be reduced and controlled by accurate and sufficient information about their disease and clinical symptoms may be controlled.
\end{abstract}

Keywords: Lichen simplex chronicus, satisfaction with life scale, STAI-TX2, Beck anxiety inventory, pruritus, patient education 
Geliş tarihi/Received: 11 Haziran 2014; Kabul tarihi/Accepted: 12 Haziran 2014

\author{
*İletişim adresi: \\ Dr. Rukiye Yasak, Dermatoloji Kliniği, Nazilli Devlet Hastanesi, Aydın. E-posta: \\ rky.yasak@net.com
}

\title{
Giriş
}

Liken simpleks kronikus (nörodermatit) sık görülen ve kaşıntıyla seyreden kronik bir deri hastalığıdır. Aşırı kaşınmaya ikincil olarak deride likenifikasyon gelişir. Daha çok erişkinlerde görülür. Genellikle obsesif kişilik bozukluğu gösteren kişilerde görülen bir hastalık tablosudur $[1,2]$. Bu hastaların bir ankisiyete bozukluğuna sahip oldukları gösterilmiştir [3]. Karşı konulmaz kaşıntı hissi esas yakınma olup bunu kronik kaşıma eylemi takip eder. Bazı hastalarda kaşınma heyecan verici, kontrolsuz bir eyleme dönüşebilir ve bilinçli bir şekilde, kaşıntının yerini "rahatlatıcı" mazoşistik bir acı ve yanma hissi alıncaya kadar bir kriz şeklinde sürdürür. Bu olgularda ankisiyete kaşıma eylemiyle yatıştırılmaya çalışılmaktadır. Tedavisi genellikle semptoma yönelik olup topikal kortikosteroidler ve sistemik antihistaminikler kullanılmaktadır. Kronik bir seyir gösteren liken simpleks kronikusta tedavi ile geçici düzelmeler sağlansa bile kolayca tekrar edebilmektedir [1,2].

$\mathrm{Bu}$ çalışmamızdaki amacımız hastayı hastalıkla ilgili bilgilendirmenin yanı sıra bir bilgilendirme broşürü ve emolyent kullanarak liken simpleks kronikuslu olgularda semptomların yatıştırılarak oluşan plakların temizlenmesinin sağlanabileceğini göstermektir.

\section{Gereç ve yöntem}

Çalışmaya Nazilli Devlet Hastanesi Dermatoloji Polikliniği'ne Aralık 2013-Nisan 2014 tarihleri arasında başvuran 21 Liken simpleks kronikuslu hasta alındı (16 kadın, 5 erkek). Araştırmaya alınma ölçütleri en az ilkokul mezunu olmak, ciddi bir fiziksel hastalık ve kaşıntıya neden olabilecek herhangi bir iç hastalığın bulunmaması, psikiyatrik ilaç kullanmıyor olması ve çalışmaya katılmayı kabul etme olarak belirlendi.

Hastalar, dermatoloji polikliniğinde hastalıkları hakkında araştırmacı tarafından, hastada beliren kaşıntının psikolojik kökenli bir kaşıntı olduğu ve kaşıntı-kaşıma siklusunun kendi iradeleri ve emolyent kullanılarak önlenebileceğini vurgulayan broşür içeriği çerçevesinde bilgilendirildi. Sonra broşür hastalara verilerek geçerlilik ve güvenilirlikleri yapılmış olan Yaşam Doyumu Ölçeği [4, 5], Süreklilik Kayg1 Ölçeği [6], Beck Ankisiyete Ölçeği [7] ve kaşıntı şiddeti için $0-10$ arasında (0 hiç yok, 10 çok şiddetli) puanlama yapılan görsel analog skala uygulandı [8].

Yaşam doyumu ölçeğinde mutluluğa ulaşabilmede, bireyin hedefleriyle, bu hedeflere hangi ölçüde ulaşabildiği konusundaki fikirleri arasındaki uyum ya da uyumsuzluğun belirleyici rol oynadığı öne sürülmektedir. Yüksek puanlar yaşam doyumunun yüksek olduğunu ifade etmektedir [4, 5]. Süreklilik Kaygı Ölçeği (STAI II) bireyin içinde bulunduğu durum ve koşullardan bağımsız olarak kendini nasıl hissettiğini belirler. Alınabilecek toplam puanlar 20-80 arasında değişir ve yüksek puanlar kaygı düzeyinin artışını gösterir [6]. Beck Ankisiyete Ölçeği dörtlü Likert tipte bir ölçektir ve alınan puanların yüksekliği ankisiyetenin şiddetini gösterir [7].

Hastalara iki hafta sonra kontrole çağırıldıklarında yapılan bilgilendirme ve broşürün etkilerini değerlendirmek için Beck Ankisiyete Ölçeği ve görsel analog skala tekrar uygulandı. İstatiksel analizler için çalışmanın verileri SPSS (Statistical Pactage for Social Sciences) programının 15,0 versiyonuna yüklendi. Verilerin değerlendirilmesinde Spearman korelasyon analizi ve Wilcoxon testi kullanıld1. 


\section{Bulgular}

Yaşam Doyumu Ölçeği, Süreklilik Kaygi Ölçeği, Beck Ankisiyete Ölçeği ve görsel analog skala değerleri arasında ilk muayenede istatistiksel olarak anlamlı bir korelasyon saptanamad1 $(p>0,05)$. Elde edilen diğer veriler yaş ve cinsiyet arasında karşılaştırıldığında istatistiksel olarak anlamlı fark yoktu ( $p>0,05)$.

İlk muayene ve kontrol muayenesinde Beck Ankisiyete Ölçeği değerleri arasında istatistiksel olarak anlamlı bir fark tespit edildi. Kontrolde elde edilen Beck ankisiyete değerleri daha düşük bulundu $(Z=-3,204 ; p<0,05)$. Kontrol muayenesinde elde edilen görsel analog skala puanları ilk muayenede elde edilenlerden daha düşüktü. İlk muayenede ve kontrol muayenesinde elde edilen görsel analog skala değerleri karşılaştırıldığında aralarındaki fark istatistiksel olarak anlamlı bulundu ( $\mathrm{Z}=-3,683$; $\mathrm{p}<0,05)$.

Tedavi sonrası Beck ankisiyete puanları ve görsel analog skala puanları arasında istatistiksel olarak anlamlı bir korelasyon saptand1 $(r=0,446 ; \mathrm{p}<0,05)$.

\section{Tartışma}

Liken simpleks kronikus tedavisi çok yönlü bir yaklaşımı gerektirir. Kronik seyirli olan hastalık dermatolojik tedavi ile geçici düzelmeler sağlasa bile yinelemeler sıktır. En küçük bir psişik stres kaynağı başlatıcı olabilir [1, 2]. Dermatoloji polikliniklerinde topikal kortikosteroidler, antihistaminikler ve ankisiyete önleyici ilaç tedavileri birincil seçenekler olarak kullanılmaktadır. Bu hastalar hastalığın kronik seyri nedeniyle uzun süreli topikal kortikosteroid tedavileri almak zorunda kalmaktadırlar. Son yıllarda liken simpleks kronikusun topikal tedavisinde takrolimus gibi yeni ajanlar da dahil olmuştur [9]. Yine fototerapi uygulamaları da liken simpleks kronikus tedavisinde kullanılabilecek alternatifler arasında yer alabilir [10]. Liken simpleks kronikuslu olgularda davranışsal tedavi yaklaşımları da denenmiş ve olumlu sonuçlar alınmıştır [11].

Yaşam doyumu bireyin ekonomik, fiziksel ve ruhsal durumu ile genel olarak yaşamını nasıl değerlendirdiğini içermektedir ve ankisiyete bozukluğu olanlarda yaşam doyumunun da azalması beklenir [12]. Çalışmamızda hastalarımıza ait ankisiyete puanları ile yaşam doyumu puanları arasında bir korelasyon gösterilememiştir. Aynı şekilde süreklilik kaygı puanlarıyla ankisiyete puanları arasında da bir ilişki gösterilememiştir. Yaşam boyu doyum ve süreklilik kaygı ölçekleri bireylerin kendilerini daha ziyade yaşam boyu değerlendirmelerine olanak sağlayan ölçeklerdir. Oysa Beck ankisiyete ölçeği son bir hafta içinde bireyin içinde bulunabileceği kaygıyı belirleyebilmektedir. Bu sonuçlara göre liken simpleks kronikus olgularında kaşıntı gibi semptomları tetikleyen stres kaynağının yakın zamana ait etmenlerden oluştuğu düşünülmeli ve hasta bu açıdan değerlendirilmelidir.

Liken simpleks kronikus olgularında ilk ve zorunlu hedef, kaşıntı hissinin ortadan kaldırılmasıdır [1, 2]. Hastanın kaşınan alan veya alanları mümkün olduğunca kaşımamaya gayret göstermesini vurgulamak önemlidir. Yaptığımız çalışmada iki haftalık topikal nemlendirici ve hasta bilgilendirilmesi uygulaması ile hem görsel analog skala değerlerinde hem de Beck ankisiyete değerlerinde istatistiksel olarak anlamlı azalmalar gözlenmiştir. Ankisiyete liken simpleks kronikus olguları için önemli bir tetikleyicidir. Bununla birlikte liken simpleks kronikusta ortaya çıkan kaşıntının nedenlerinin hastaya iyi anlatılabilmesi hem kaşıntının emolyentlerle bile kolayca kontrolünü sağlar hem de hastanın ankisiyetesi üzerine olumlu bir etki oluşturabilir.

Liken simpleks kronikus günlük dermatoloji pratiğinde genellikle bir kronik ekzema gibi değerlendirilir ve buna yönelik tedavi uygulanır. Özellikle son yıllarda kronik hastalıklardaki hızlı artış sosyal ve ekonomik maliyetleri de olumsuz etkilemektedir [12]. $\mathrm{Bu}$ nedenle liken simpleks kronikus gibi kronik ve temelde psikolojik etmenlerin öncelikli rol oynadığı hastalıklar hakkında hastalara yeterli açıklamaların yapılmaması hem hastalığın kronik seyrini daha güçlendirecek hem de tedavi maliyetlerini olumsuz 
etkileyecektir. $\mathrm{Bu}$ açıdan altta yatan nedene yönelik yaklaşımlarla tedavilerin planlanması, başa çıkma yollarının öğretilmesi önemlidir. Çalışmamızda yalnızca bilgilendirme broşür ve emolyent kullanılarak hastalarda anlamlı semptomatolojik düzelme sağlanırken ankisiyetede azalma elde edilebilmiştir.

Liken simpleks kronikuslu olgularda bireyin yaşam boyu kendini değerlendirmesiyle ilgili yaşam doyumu, süreklilik kaygı durumu ve hastalıkla ilgili semptomlar arasında bir ilişki bulunmamaktadır. Bu olgularda kısa dönemde ortaya çıkmış olan kaygı ve buna bağlı gelişen kaşıntı hissi, hastalıkla ilgili doğru ve yeterli bilgilendirmeyle azaltılabilir ve hastalığın klinik kontrolü sağlanabilir.

\section{Kaynaklar}

1. Braun-Falco O, Plewig G, Wolff HH, Landthaler M. Pruritis and Prurigo. Third edition, Italy, Springer Verlag 2009; 446.

2. Millard LG, Cotterill JA. Psychocutaneous Disorders. Rook's Textbook of Dermatology; Ed. Burns T, Breahnach S, Lox N, Griffiths C. seventh edition, Massachusetts, Blackwell Science Publ 2004; 61: 1-41.

3. Liao YH1, Lin CC, Tsai PP, Shen WC, Sung FC, Kao CH. Increased risk of lichen simplex chronicus in people with anxiety disorder: A nationwide population-based retrospective cohort study. Br J Dermatol 2014; 170: 890-4.

4. Diener E, Enmors RA, Larger RJ ve ark. The satisfaction with life scale. J Pers Assess 1985; 49: 71-5.

5. Gündoğar D, Sallan Gül S, Uskun E. Üniversite öğrencilerinde yaşam doyumunu yordayan etkenlerin incelenmesi. Klinik Psikiyatri 2007; 10: 14-27.

6. Tuncer G, Yucel S; Comfort and anxiety levels of women with early stage breast cancer who receive radiotherapy. Asian Pacific J Cancer Prevent 2014; 15: 2109 14.

7. Bahar A, Bahar G, Savaş H, Parlar S. Engelli çocukların annelerinin depresyon ve ankisiyete düzeyleri ile başa çıkma tarzlarının belirlenmesi. Fırat Sağlık Hizmetleri Dergisi 2009; 11: 97-112.

8. Susel J, Batycka-Baran A, Retch A. Uraemic pruritis markedly affects the Quality of life and depressive symptoms in haemodialysis patients with end-stage renal disease. Acta Derm Venereol 2004; 94: 276-281.

9. Tan ES, Tan AS, Tey HL. Effective treatment of scrotal lichen simplex chronicus with $0.1 \%$ tacrolimus ointment: An observational study. J Eur Acad Dermatol Venereol. 2014 Mar 25. doi: 10.1111/jdv.12500. [Epub ahead of print].

10. Virgili A, Minghetti S, Borghi A, Corazza M. Phototherapy for vulvar lichen simplex chronicus: An "off-label use" of a comb light device. Photodermatol Photoimmunol Photomed. 2014 Mar 3. doi: 10.1111/phpp.12120. [Epub ahead of print].

11. Hisli ŞN, Durak BA, Uzun C. Ankisiyete bozukluğu: Kişiler arası tarz, kendilik algıs1 ve öfke açısından bir değerlendirme. Anadolu Psikiyatri Derg 2011; 12: 107-13.

12. Divajeva D, Marsh T, Logstrup S, Kestens M, Vemer P, Kriaucioniene V, Peresson S, O'Kelly S, Rito A, Webber L. Economics of chronic diseases protocol: Cost-effectiveness modelling and the future burden of noncommunicable disease in Europe. BMC Public Health 2014; 14: 456. 